\title{
TRACER STUDIES OF THE ABSORPTION AND FATE OF STEROID HORMONES IN MAN ${ }^{1}$
}

\author{
By LEON HELLMAN, H. LEON BRADLOW, E. L. FRAZELL, AND T. F. GALLAGHER \\ (From the Divisions of Biophysics, Steroid Metabolism and Biochemistry, Sloan-Kettering \\ Institute for Cancer Research, the Head and Neck Service, Memorial Center \\ and the Sloan-Kettering Division, Cornell University Medical \\ College, New York, N. Y.)
}

(Submitted for publication December 9, 1955 ; accepted May 17, 1956)

The steroid hormones testosterone, hydrocortisone and corticosterone present certain paradoxical physiological problems in their transport and metabolism in the organism. Thus hydrocortisone is highly effective orally whereas testosterone has little biological activity when fed. Insofar as man and the rodent are concerned, there appears to be no appreciable species difference in the response to these two hormones when given by mouth. On the other hand, there is a striking difference in the manner in which these two species eliminate the end product of hormone metabolism (1-3) and, in addition, dissimilar compounds are formed and excreted by each. A further species difference exists in that hydrocortisone is the principal product of the adrenal secretion in man, whereas in the rat corticosterone appears to be the major component (4).

Since an interpretation of these differences might give a deeper insight into the mechanism of hormonal action, an exploration of the problems implicit in these facts was undertaken. First the possibility was entertained that corticosterone might behave like a hormone "foreign" to the human and would, as a consequence, differ from the "normal" secretion, hydrocortisone, in either the rate or route of elimination of its metabolites. Second, cortisone acetate was compared with hydrocortisone and corticosterone to establish, by the same criteria, whether similar processes are operative with the biologically active ester as with the free hormones. Third, testosterone was given by both the oral and intravenous route in order to

1 This investigation was carried out under contract AT30-1 910 with the United States Atomic Energy Commission and supported in part by a research grant (C-440) from the National Cancer Institute of the National Institutes of Health of the United States Public Health Service, and a research grant from the American Cancer Society. have a comparison of a chemically similar steroid hormone, differing in biological activity, with the two adrenal hormones. Fourth, the absorption of hydrocortisone and testosterone from the intestinal tract was studied in human subjects with the thoracic duct cannulated. Fifth, the importance of biliary excretion in the human was evaluated in patients with complete biliary fistulas. The results reported are of interest for the comparative physiology of the hormones since the findings obtained in other species can now be related to the sequence of events observed with the human.

\section{EXPERIMENTAL}

The subjects studied were patients in a metabolic ward. The pertinent clinical data concerning these patients are summarized in Table $I$. The three subjects with bile fistula, FBT-1, T-3, B-1, were studied in the interval between the two stages of an operative attempt to correct bile duct obstruction as the result of a tumor. In each case the fistula was deliberately established during the first operative procedure by complete diversion of bile flow to the exterior through an indwelling cannula. The completeness of the fistula was confirmed by the absence of bile pigments in the feces. The subjects with thoracic duct fistulas were operated upon for the purposes of this study and a polyethylene cannula was inserted through a supraclavicular incision into the left thoracic duct (5). The patients were fed a meal containing fat before the operation in order to distend the thoracic duct to facilitate insertion of the cannula.

During the early portion of each study, urine specimens were obtained through a catheter. Complete collections of urine and feces were continued for varying periods after the administration of the labelled material. Blood samples were collected with heparin as the anticoagulant. Radioactivity assays were carried out by the two procedures previously described (6) both in the infinitely thick and in the infinitely thin regions. The values reported are the average of the two counting techniques, which agreed within less than 5 per cent. Conjugated and free urinary steroids were separated by the procedure of de Courcy, Bush, Gray, and Lunnon (7); 
TABLE I

Clinical data

\begin{tabular}{|c|c|c|c|c|c|}
\hline Subject & Experiment & Sex & Age & Diagnosis & Remarks \\
\hline FT-1 & $1,2,3,6 \mathrm{D}, 7 \mathrm{~B}$ & F & 65 & Diabetes. Kimmelstiel- & Minimal edema. Proteinuria. Good \\
\hline F-5 & 4 & $\mathbf{M}$ & 39 & Multiple sclerosis & $\begin{array}{l}\text { Good general condition. Normal liver } \\
\text { and kidney function. }\end{array}$ \\
\hline Eac-1 & 5 & $\mathrm{~F}$ & 70 & Carcinoma of breast & $\begin{array}{l}\text { Good general condition. Normal liver } \\
\text { and kidney function. }\end{array}$ \\
\hline$T-1$ & $6 \mathrm{~A}$ & $\mathbf{M}$ & 44 & Aplastic anemia & $\begin{array}{l}\text { Good general condition. Required fre- } \\
\text { quent transfusions. }\end{array}$ \\
\hline $\mathrm{T}-2$ & $6 \mathrm{~B}, 6 \mathrm{C}$ & $\mathbf{M}$ & 70 & Carcinoma of prostate & $\begin{array}{l}\text { Good general condition. Normal liver } \\
\text { and kidney function. }\end{array}$ \\
\hline$\underset{T-4}{T-6}$ & $\begin{array}{l}7 \mathrm{~A} \\
8\end{array}$ & $\begin{array}{l}M \\
M\end{array}$ & $\begin{array}{l}31 \\
69\end{array}$ & $\begin{array}{l}\text { Normal } \\
\text { Carcinoma of tongue }\end{array}$ & $\begin{array}{l}\text { Excellent health. } \\
\text { Poor general condition. Thoracic duct } \\
\text { cannulated. }\end{array}$ \\
\hline FT-2 & 9,10 & $\mathbf{M}$ & 40 & Carcinoma of tongue & $\begin{array}{l}\text { Poor general condition. Thoracic duct } \\
\text { cannulated. }\end{array}$ \\
\hline FBT-1 & $11,12,13 \mathrm{~A}, 14$ & $\mathbf{F}$ & 57 & Carcinoma of gall bladder & $\begin{array}{l}\text { Fair general condition. Complete bile } \\
\text { fistula. }\end{array}$ \\
\hline$T-3$ & 13B & $\mathbf{M}$ & 60 & Carcinoma of stomach & $\begin{array}{l}\text { Fair general condition. Complete bile } \\
\text { fistula. }\end{array}$ \\
\hline B-1 & 15 & F & 60 & Carcinoma of gall bladder & $\begin{array}{l}\text { Fair general condition. Complete bile } \\
\text { fistula. }\end{array}$ \\
\hline
\end{tabular}

radioactivity in the blood was measured as previously described (6).

The testosterone-4-C ${ }^{142}$ had a specific activity of 0.52 $\mu \mathrm{c}$. per mg. Reverse isotopic dilution established that the material was at least 91 per cent pure and that $\Delta^{4}$-androstene-3,17-dione-4-C $\mathrm{C}^{14}$ was a minor impurity. The hydrocortisone-4-C ${ }^{14}$, cortisone-4- $\mathrm{C}^{14}$ acetate and corticosterone-4- $\mathrm{C}^{14}$ were obtained from the Endocrinology Study Section of the United States Public Health Service (Dr. Sam Hall) and had specific activities of $4.4 \mu \mathrm{c}$. per mg., $1.2 \mu \mathrm{c}$. per mg., and $4.4 \mu \mathrm{c}$. per mg., respectively. ${ }^{3}$ For intravenous administration, a sterile solution was freshly prepared as described previously (6) and a known quantity was then infused over a 30-minute period. In those experiments where the hormones were administered orally, a solution, prepared in an identical manner with that used for the intravenous doses, was ingested by the patients who had been fasted for at least 12 hours. The patients with the thoracic duct fistulas received the steroids orally by stomach tube in a milk and cream suspension.

\section{RESULTS}

\section{Oral hydrocortisone}

Three studies, experiments 2,3 , and 4 , are reported in Table II. The cumulative excretion of radioactivity in urine and the rate of ex-

2 Synthesized by Dr. R. B. Turner of the Rice Institute, Houston, Texas, and generously furnished by him.

3 The hydrocortisone-4-C $C^{14}$ was found to be 93 to 94 per cent pure by several investigators using a variety of techniques. The corticosterone-4-C $C^{16}$ was about 96 to 97 per cent pure. Cortisone-4-C $\mathrm{C}^{14}$ acetate was about 94 per cretion of radioactivity derived from experiment 4 (Subject F-5) are shown in Figures 1 and 2. For convenience of interpretation, typical curves after intravenous administration of hydrocortisone taken from the previous report (6) are also shown in these figures. Subjects FT-1 (two experiments) and F-5 excreted from 61 to 70 per cent of the radioactivity of the hydrocortisone within 24 hours. The results after intravenous administration of hydrocortisone to the same subject FT-1 in experiment 1 are quite similar to those of the oral experiments.

\section{Cortisone acetate}

In experiment 5, cortisone acetate was given orally to subject Eac-1. Figures 1 and 2 indicate that the initial rate of excretion was somewhat different than that of free hydrocortisone. However, the cumulative excretion of radioactivity from the esterified steroid was not significantly different from that observed after the administration of free hydrocortisone; 61 per cent was excreted in the first day with a total of 75 per cent appearing in the urine at the end of 3 days.

cent pure and contained about 4 per cent of the free alcohol. The information about the purity of these compounds was a personal communication from the Endocrinology Study Section. 
TABLE II

Excretion of radioactivity following administration of $C^{14}$ labelled steroids to intact subjects

\begin{tabular}{|c|c|c|c|c|c|c|c|c|}
\hline $\begin{array}{c}\text { Experiment } \\
\text { Subject } \\
\text { Substance } \\
\text { Dose (mg.) } \\
\text { Dose (mc.) } \\
\text { Route }\end{array}$ & $\begin{array}{c}1 \\
\text { FT-1 } \\
\text { Hydro- } \\
\text { cortisone } \\
0.15 \\
0.67 \\
\text { I.V. }\end{array}$ & $\begin{array}{c}2 \\
\text { FT-1 } \\
\text { Hydro- } \\
\text { cortisone } \\
0.11 \\
0.54 \\
\text { Oral }\end{array}$ & $\begin{array}{c}\text { 3 } \\
\text { FT-1 } \\
\text { Hydro- } \\
\text { cortisone } \\
0.18 \\
0.86 \\
\text { Oral }\end{array}$ & $\begin{array}{c}\text { F.5 } \\
\text { Fydro- } \\
\text { cortisone } \\
0.20 \\
0.94 \\
\text { Oral }\end{array}$ & $\begin{array}{c}5 \\
\text { Eac-1 } \\
\text { Cortisone } \\
\text { Acetate } \\
0.25 \\
0.96 \\
\text { Oral }\end{array}$ & $\begin{array}{c}\text { 6D* } \\
\text { FT-1 } \\
\text { Testos- } \\
\text { terone } \\
2.5 \\
1.6 \\
\text { I.V. }\end{array}$ & $\begin{array}{c}7 \mathrm{~A} \\
\mathrm{~T}-4 \\
\text { Testos- } \\
\text { terone } \\
1.5 \\
0.77 \\
\text { Oral }\end{array}$ & $\begin{array}{c}7 B \\
\text { FT-1 } \\
\text { Testos- } \\
\text { terone } \\
2.7 \\
1.7 \\
\text { Oral }\end{array}$ \\
\hline
\end{tabular}

Time: hours

Urinary Radioactivity: Per Cent Dose

\begin{tabular}{|c|c|c|c|c|c|c|c|c|}
\hline $\begin{array}{c}0-1 \\
1-2 \\
2-3 \\
3-4 \\
4-5 \\
5-6 \\
6-12 \\
12-18 \\
18-24 \\
24-48 \\
48-72 \\
72-96\end{array}$ & $\begin{array}{r}2.0 \\
6.2 \\
8.4 \\
6.0 \\
5.6 \\
5.4 \\
15.5 \\
7.7 \\
11.3 \\
7.5 \\
13.6 \\
11.4\end{array}$ & $\begin{array}{c}3.9 \\
5.1 \\
6.2 \\
5.8 \\
4.3 \\
4.3 \\
17.5 \\
12.0 \\
7.4 \\
0 \\
0\end{array}$ & $\begin{array}{r}3.3 \\
6.5 \\
5.9 \\
5.2 \\
4.1 \\
4.6 \\
9.0 \\
18.4 \\
4.6 \\
13.8\end{array}$ & $\begin{array}{r}6.8 \\
15.4 \\
11.2 \\
8.4 \\
6.8 \\
4.3 \\
9.3 \\
3.3 \\
8.2 \\
8.6 \\
2.9 \\
3.4\end{array}$ & $\begin{array}{r}2.8 \\
4.3 \\
4.0 \\
5.4 \\
4.2 \\
5.3 \\
17.8 \\
10.1 \\
7.1 \\
11.9 \\
1.9 \\
0\end{array}$ & $\begin{array}{r}4.5 \\
8.3 \\
7.3 \\
4.0 \\
3.6 \\
2.2 \\
11.3 \\
5.7 \\
2.0 \\
3.6\end{array}$ & $\begin{array}{r}24.6 \\
19.0 \\
5.8 \\
6.5 \\
3.6 \\
2.4 \\
5.6 \\
1.7 \\
1.5 \\
4.9 \\
4.6 \\
3.9\end{array}$ & $\begin{array}{r}12.1 \\
11.4 \\
5.9 \\
4.9 \\
3.9 \\
3.0 \\
11.1 \\
4.9 \\
4.2 \\
5.9 \\
0\end{array}$ \\
\hline
\end{tabular}

Total :

\begin{tabular}{ccccccccc}
\hline 24 hours & 68.1 & 66.5 & 61.6 & 70.4 & 61.0 & 50.0 & 75.6 & 61.4 \\
$T_{3}^{2}:$ hourst & 1.5 & 2 & 4 & 2 & 3 & 3 & 1.5 & 2 \\
$T_{3}^{1}:$ hourst & 17 & 10 & 34 & 13 & 13.5 & 13 & 35 & 11 \\
\hline
\end{tabular}

* Experiment 6A, Subject T-1, I.V. Testosterone, 53\% excreted in 24 hours.

Experiment 6B, Subject T-2, I.V. Testosterone, $60 \%$ excreted in 24 hours.

Experiment 6C, Subject T-2, I.V. Testosterone, $55 \%$ excreted in 24 hours.

No fractional urine collections were made in Experiments $6 \mathrm{~A}, \mathrm{~B}$, and $\mathrm{C}$.

$+T_{1}^{2}$ describes the rapid component in terms of "half-life" and $T_{1}^{1}$, the slow component, of the rate of excretion of hormone metabolites.

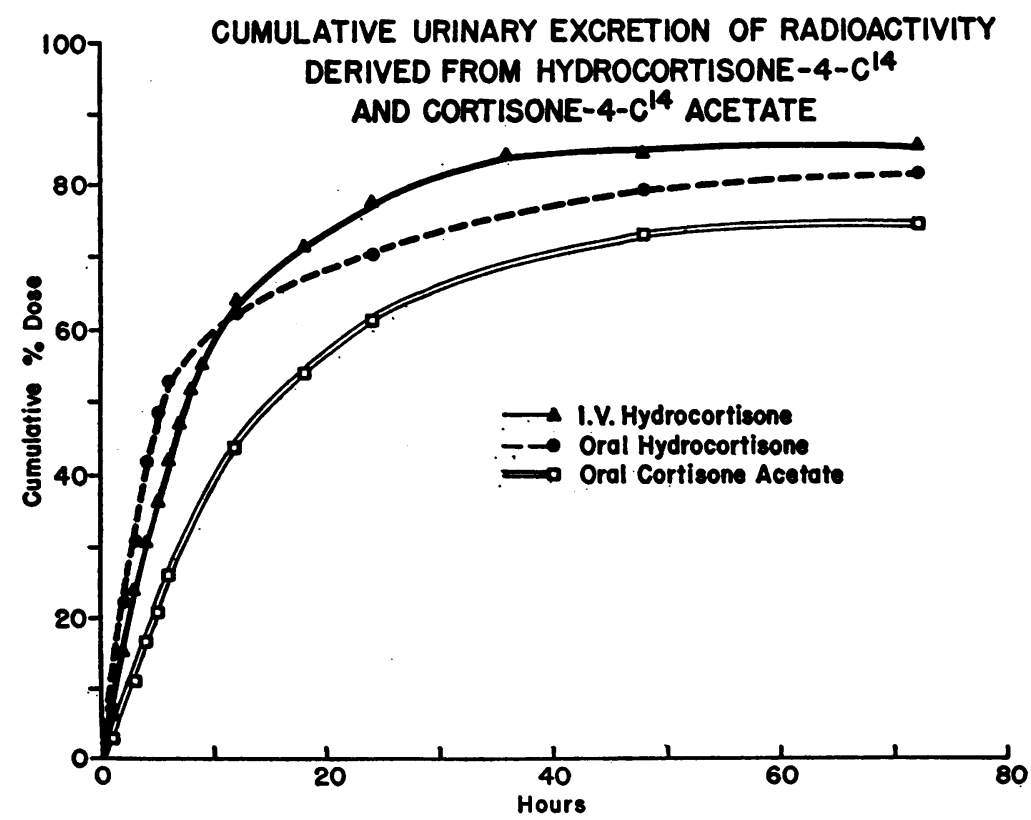

Fig. 1. Cumulative Urinary Excretion of Radionctivity Derived from

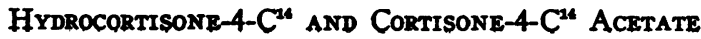




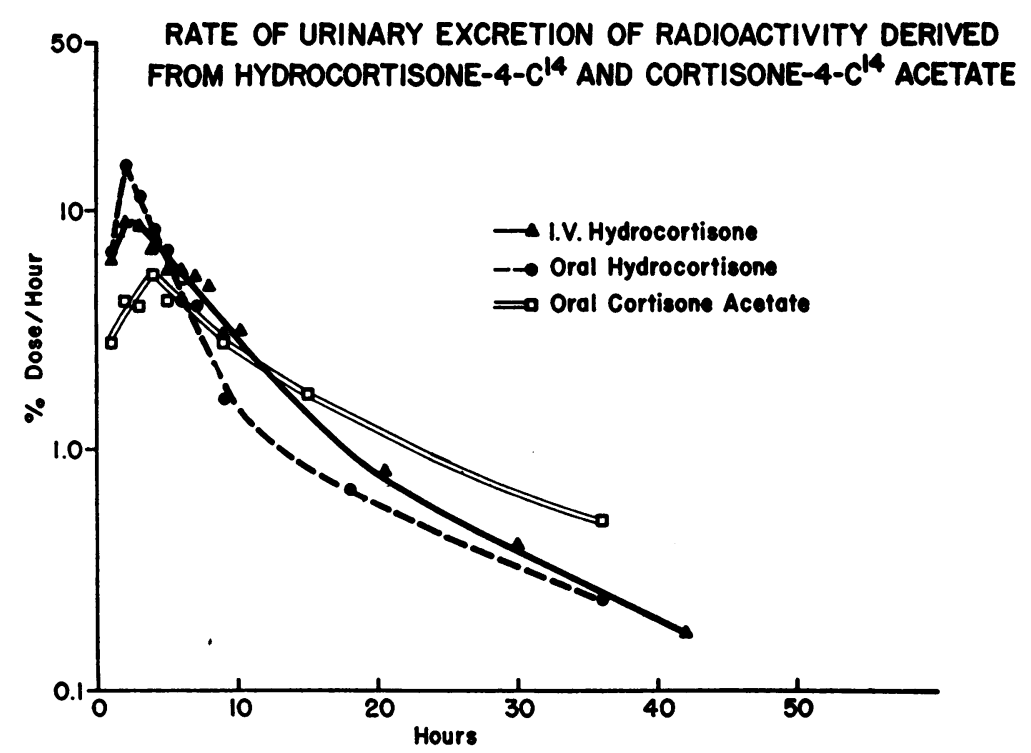

Fig. 2. Rate of URinary Excretion of Radioactivity Derived from Hydrocortisone-4-C ${ }^{14}$ AND CoRTisone-4-C ${ }^{14}$-ACETATE

\section{Testosterone}

Results following the oral and intravenous administration of testosterone-4-C $\mathrm{C}^{14}$ to male and female subjects are given in Table II and Figure 3. Two male subjects, $\mathrm{T}-1, \mathrm{~T}-2$, received testosterone intravenously (experiments $6 \mathrm{~A}, 6 \mathrm{~B}$, and $6 \mathrm{C}$ ) and 53 to 60 per cent of the administered radioactivity appeared in the urine within 24 hours. The female subject, FT-1, excreted 50 per cent during the first day following intravenous testosterone (experiment $6 \mathrm{D}$ ) and 61 per cent of the radioactivity of orally administered testosterone in the first 24 hour period (experiment 7B). A normal male subject, T-4, excreted 76 per cent of oral testosterone radioactivity during the first day (experiment 7A). The rate of excretion of the metabolites of

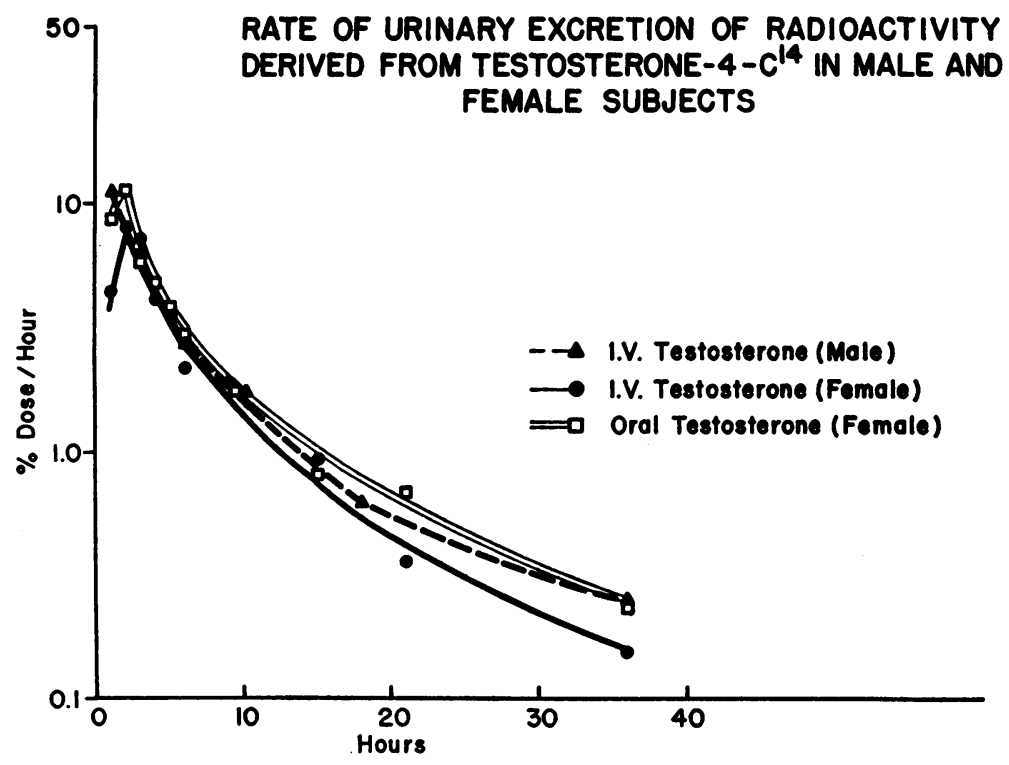

Fig. 3. Rate of Urinary Excretion of Radioactivity Derived from Testosterone-4-C ${ }^{n}$ in Male and Female Subjects 
testosterone was similar in male and female subjects following oral or intravenous administration, and resembled the rate of excretion after hydrocortisone in both the current studies and those previously reported.

\section{Studies in patients with thoracic duct fistulas}

Table III contains the data for experiments 8 , 9 , and 10 concerning the excretion of metabolites of hydrocortisone and testosterone following the administration of these hormones to subjects with thoracic duct fistulas. In experiment 8, 40 per cent of hydrocortisone radioactivity appeared in the urine within 10 hours and the complete collection of lymph made during this period failed to contain any significant amount of radioactivity. The result was confirmed in another subject, FT-2, in whom 17 per cent of the radioactivity appeared in the urine within 4 hours; during this period no radioactivity was present in lymph. In order to test the possibility that a different route of $a b-$ sorption might be responsible for the biological inactivity of oral testosterone, the same subject, FT-2, received labelled testosterone in experiment 10. Sixty per cent of the metabolites of testosterone appeared in the urine within 24 hours and the complete lymph collection made during that period was devoid of any radioactivity.

\section{Experiments in patients with biliary fistulas}

Table IV and Figures 4 and 5 give the data concerning the administration of hydrocortisone, testosterone and corticosterone to two subjects with complete biliary fistulas. These experiments were done in order to study the presence or absence in man of an enterohepatic circulation, known to occur in rodents, for hormones and metabolites. Following the intravenous administration of small and large doses of hydrocortisone in experiments 11 and 12 to subject FBT-1, about 80 per cent of the radioactivity appeared in the urine in each instance within 24 hours with negligible excretion in the bile. During this period bile was completely diverted to the exterior, so that the absence of radioactivity in the bile and the presence of the expected amount in the urine indicate conclusively that biliary excretion of metabolites of the hormone was negligible in this subject. Experiments 11 and 12 were at different dose levels, $0.25 \mathrm{mg}$. and
TABLE III

Excretion of radioactioity following oral C14 labelled steroids in patients with thoracic duct fistulas

\begin{tabular}{|c|c|c|c|}
\hline $\begin{array}{c}\text { Experiment } \\
\text { Subject } \\
\text { Substance } \\
\text { Dose (mg.) } \\
\text { Dose (mg.) } \\
\text { Route }\end{array}$ & $\begin{array}{c}8 \\
\text { F-6 } \\
\text { Hydro- } \\
\text { cortisone } \\
0.25 \\
0.65 \\
\text { Oral }\end{array}$ & $\begin{array}{c}9 \\
\text { FT-2 } \\
\text { Hydro- } \\
\text { cortisone } \\
0.25 \\
0.6 \\
\text { Oral }\end{array}$ & $\begin{array}{c}10 \\
\text { FT-2 } \\
\text { Testos- } \\
\text { terone } \\
4.2^{*} \\
3.0^{*} \\
\text { Oral }\end{array}$ \\
\hline Time: hours & \multicolumn{3}{|c|}{ Urinary Radioactivity: Per Cent Dose } \\
\hline $\begin{array}{c}0-3 \\
3-4 \\
4-6 \\
6-10 \\
10-27\end{array}$ & $\begin{array}{r}13.0 \\
6.2 \\
5.6 \\
15.9\end{array}$ & $\begin{array}{r}11.2 \\
6.2\end{array}$ & $\begin{array}{r}5.0^{*} \\
5.0 \\
10.0 \\
20.0 \\
20.0\end{array}$ \\
\hline Total & $\begin{array}{c}10 \text { hours : } \\
40.7\end{array}$ & $\begin{array}{c}4 \text { hours : } \\
17.4\end{array}$ & $\begin{array}{c}27 \text { hours } \\
60.0\end{array}$ \\
\hline Time: hours & \multicolumn{3}{|c|}{ Lymph Radioactivity: Per Cent Dose } \\
\hline $\begin{array}{c}0-2 \\
2-4 \\
4-6 \\
6-8 \\
8-10 \\
10-27\end{array}$ & $\begin{array}{l}0 \\
0 \\
0 \\
0.3 \\
0\end{array}$ & $\begin{array}{l}0 \\
0 \\
0\end{array}$ & $\begin{array}{l}0 \\
0 \\
0 \\
0 \\
0 \\
0\end{array}$ \\
\hline
\end{tabular}

* Because of some slight uncertainty in estimating the amount of cream containing the dose of labelled steroid actually received by the patient, the values in this column have been rounded off.

$100 \mathrm{mg}$., respectively, to test whether the capacity of the liver to handle the hormone might be exceeded. The identical results in both experiments indicate that, within these limits, the size of the dose is not critical for the appearance or absence of hormone metabolites in human bile.

Two experiments, $13 \mathrm{~A}$ and $13 \mathrm{~B}$, were done in a male and a female patient with complete biliary fistulas after the administration of testosterone. In both instances the expected amount of radioactivity derived from testosterone was excreted in the urine. Although there was detectable radioactivity in the bile the total excretion by this route was small.

Corticosterone was also administered to two patients with complete bile fistulas (experiments 14 and 15). As shown in Table IV, the amount of radioactivity that appeared in the urine was quite comparable with that observed after the administration of hydrocortisone; only a small fraction of the radioactivity was recovered in the bile.

The data on radioactivity found in blood after the different steroid hormones are summarized in Table V. The "free" and "conjugated" radio- 
TABLE IV

Excretion of radioactivity following $C^{14}$ labelled steroids in patients with biliary fistulas

\begin{tabular}{|c|c|c|c|c|c|}
\hline $\begin{array}{l}\text { Experiment } \\
\text { Subject } \\
\text { Substance } \\
\text { Dooe (mg.) } \\
\text { Doose (mc.) } \\
\text { Route. }\end{array}$ & $\begin{array}{c}11 \\
\text { FBT-1 } \\
\text { Hydrocortisone } \\
0.25 \\
0.85 \\
\text { I.V. }\end{array}$ & $\begin{array}{c}12 \\
\text { FBTT-1 } \\
\text { Hydrocortisone } \\
100 \\
0.68 \\
\text { I.V. }\end{array}$ & $\begin{array}{c}13 A^{*} \\
\text { FBT-1 } \\
\text { Testosterone } \\
4.2 \\
3.0 \\
\text { I.V. }\end{array}$ & $\begin{array}{c}14 \\
\text { FBT-1 } \\
\text { Corticosterone } \\
0.6 \\
0.96 \\
\text { I.V. }\end{array}$ & $\begin{array}{c}15 \\
\text { B-1 } \\
\text { Corticosterone } \\
0.6 \\
1.0 \\
\text { I.V. }\end{array}$ \\
\hline Time: hours & \multicolumn{5}{|c|}{ Urine: Per Cent Dose } \\
\hline $\begin{array}{c}0-1 \\
1-2 \\
2-3 \\
3-4 \\
4-5 \\
5-6 \\
6-12 \\
12-18 \\
18-24 \\
24-48 \\
48-72 \\
72-96\end{array}$ & 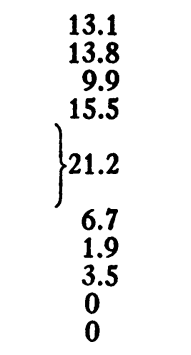 & $\begin{array}{r}15.3 \\
12.5 \\
10.0 \\
22.6 \\
15.3 \\
4.1 \\
1.8 \\
4.1 \\
1.3\end{array}$ & 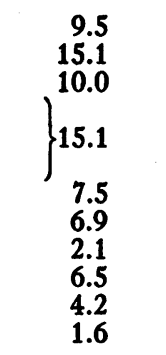 & $\begin{array}{r}3.3 \\
10.7 \\
15.8 \\
12.4 \\
8.8 \\
6.8 \\
13.2 \\
10.3 \\
3.9 \\
2.6 \\
0.8\end{array}$ & $\begin{array}{r}6.0 \\
11.2 \\
9.1 \\
8.4 \\
13.6 \\
8.0 \\
15.2 \\
3.3 \\
2.3 \\
2.3 \\
0.7\end{array}$ \\
\hline Total: 24 hours & 82.1 & 81.6 & 67. & 85.2 & 77.1 \\
\hline$T_{t}^{2}:$ hours $\dagger$ & 3.5 & 2.5 & 2.5 & 1.5 & 1.5 \\
\hline$T_{1}^{1}:$ hours $\dagger$ & 18 & 14 & 17 & 6 & 9 \\
\hline
\end{tabular}

Time: hours

\begin{tabular}{cl}
\hline $0-2$ & 0 \\
$2-4$ & 0 \\
$4-6$ & 0 \\
$6-12$ & 0.3 \\
$12-18$ & 0.2 \\
$18-24$ & 0 \\
$24-48$ & 0 \\
$48-72$ & 0 \\
$72-96$ & 0
\end{tabular}

Time: days

$0-1$
$1-2$
$2-3$
$3-4$

* Experiment 13B, Subject T-3, I.V. Testosterone, 51 per cent excreted in 24 hours in urine; 10 per cent in bile.

$+T^{2}$ describes the rapid component in terms of "half-life" and $T^{1}$, the slow component, of the rate of excretion of hormone metabolites.

activity in the urine are also shown in this table. These terms "free" and "conjugated" refer to steroid hormones or metabolites easily extracted from an aqueous medium by a relatively non-polar solvent such as chloroform, methylene chloride and the like ("free") and to steroid derivatives which remain in the aqueous phase ("conjugated"). It is recognized that these terms are not completely accurate in the strict chemical sense since the products have not been isolated and
Bile: Per Cent Dose

$\begin{array}{lll}0.05 & 0 & 0 \\ 0.2 & 0 & 0.2 \\ 0.1 & 0.3 & 0.5 \\ 0.1 & 0.1 & 1.0 \\ 0.3 & 0.1 & 0.9 \\ 0.4 & 0.3 & 0.4 \\ 0.4 & 0.2 & 0.1 \\ 0.7 & 0.1 & 0 \\ 0.5 & & 0\end{array}$

Feces: Per Cent Dose

$\begin{array}{llc}0 & 0 & 15.7 \\ 0 & 0.8 & 1.5 \\ 0 & 1.9 & 0 \\ 0.8 & 2.2 & 0.2\end{array}$

0

0.2

0.2
0.5
.0
0.9
0.1
0
0


URINARY AND BILIARY EXCRETION OF RADIOACTIVITY DERIVED FROM HYDROCORTISONE-4-C $C^{14}$, CORTICOSTERONE-4-C 14 AND TESTOSTERONE-4-C ${ }^{14}$ IN A SUBJECT WITH A COMPLETE

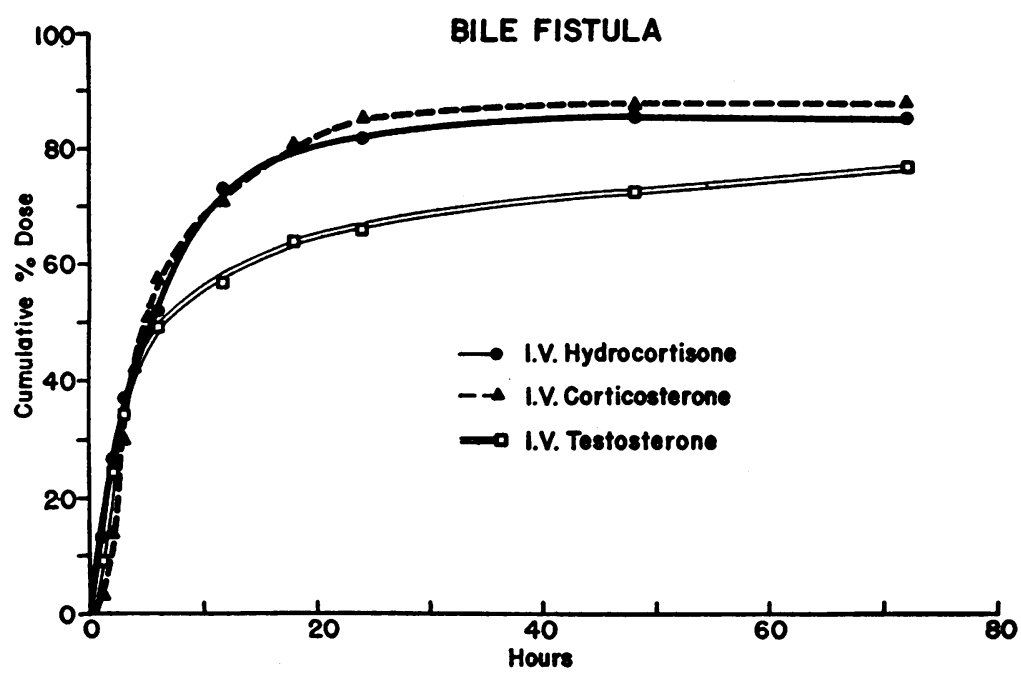

Fig. 4. Urinary and Bitiary Excretion of Radionctivity Derrved from Hydrocortisone-4-C'4, Corticosterone-4-C ${ }^{14}$ aNd Testosterone-4-C ${ }^{14}$ in a Subject with a Complete Bile Fistula

The relatively minor quantities of radioactivity excreted in bile are noted in Table IV.

RATE OF URINARY EXCRETION OF RADIOACTIVITY DERIVED FROM HYDROCORTISONE-4-C 14 , CORTICOSTERONE-4-C ${ }^{14}$ AND TESTOSTERONE-4-C 14 IN A SUBJECT WITH A COMPLETE

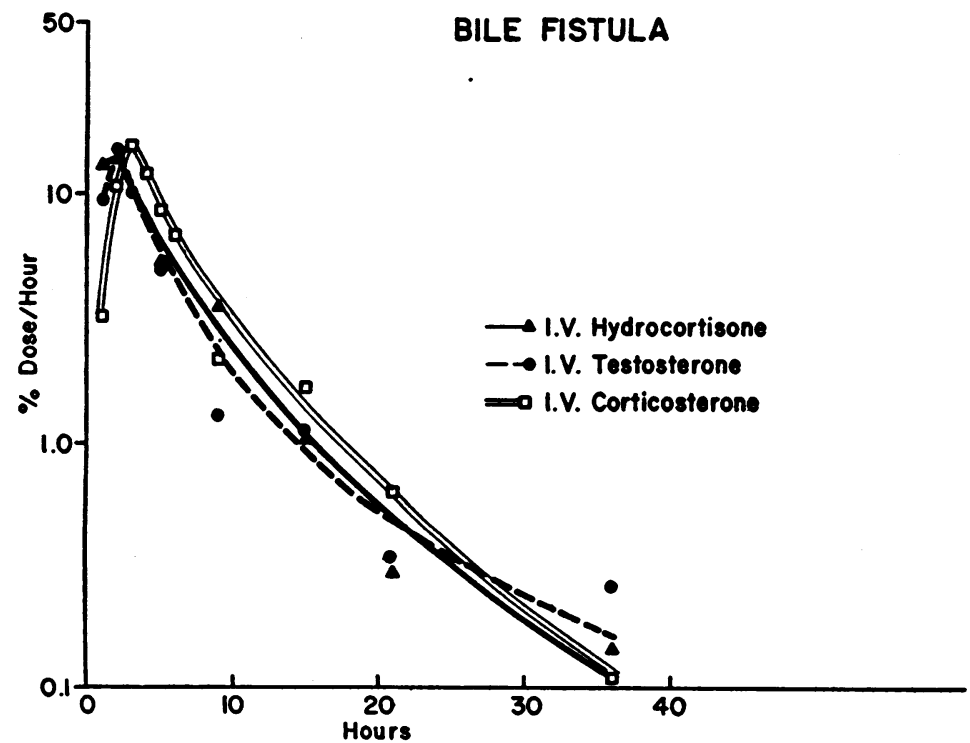

Fig. 5. Rate of Urinary Excretion of Radioactivity Derived from Hydrocortisone-4-C $C^{14}$, Corticostrrone-4-C $C^{14}$ AND Testosterone-4-C ${ }^{26}$ IN A Subject with a Complete Bine Fistula 
TABLE V

Blood levels and conjugated urinary radioactivity

\begin{tabular}{|c|c|c|c|c|c|}
\hline \multicolumn{3}{|c|}{ Blood levels } & \multicolumn{3}{|c|}{$\begin{array}{l}\text { "Conjugated" urinary } \\
\text { radioactivity }\end{array}$} \\
\hline $\begin{array}{l}\text { Experi- } \\
\text { ment }\end{array}$ & $\begin{array}{l}\text { Time: } \\
\text { min. }\end{array}$ & $\begin{array}{c}\% \\
\text { Dose/ } \\
\text { Liter }\end{array}$ & $\begin{array}{l}\text { Experi- } \\
\text { ment }\end{array}$ & $\begin{array}{l}\text { Time: } \\
\text { hours }\end{array}$ & $\begin{array}{c}\% \\
\text { Conju } \\
\text { gated }\end{array}$ \\
\hline $\begin{array}{c}4 \\
7 \mathrm{~A} \\
11 \\
12 \\
13 \mathrm{~A}\end{array}$ & $\left\{\begin{array}{r}40 \\
120 \\
210 \\
45 \\
38 \\
45 \\
45\end{array}\right.$ & $\begin{array}{l}0.82 \\
0.0 \\
0.0 \\
2.63 \\
1.29 \\
2.07 \\
1.84\end{array}$ & $\begin{array}{r}3 \\
4 \\
6 \\
11 \\
14 \\
15\end{array}$ & $\begin{array}{c}1-2 \\
1-1.5 \\
1-2 \\
13-18 \\
1-2 \\
13-18 \\
1-2\end{array}$ & $\begin{array}{r}94 \\
95 \\
100 \\
100 \\
94 \\
98 \\
96\end{array}$ \\
\hline
\end{tabular}

DISCUSSION

Significance of measurements of total radioactivity for the study of hormone metabolism

In these studies the detection of radioactivity following the administration of steroid hormones labelled with radiocarbon at C-4 is interpreted as evidence for the presence either of the hormone or in vivo chemical transformation products which still possess the steroid ring structure. This interpretation is supported by three independent types of evidence. 1) To all practical purposes none of the $\mathrm{C}^{14}$ at carbon-4 is found in the expired carbon dioxide after the administration of hydrocortisone (6) or testosterone (2). This is evidence that at least Ring $A$, is not degraded to small fragments. 2) A very large portion of the excreted radioactivity following administration of either of these hormones can be extracted into organic solvents following hydrolysis of the conjugated metabolites and most of this radioactivity is recovered in the neutral steroid fraction. 3) A considerable portion of the total radioactivity of the neutral fraction has been recovered in the form of identified metabolites of hydrocortisone (8) in which the condensed ring structure is still intact. Almost all the urinary metabolites of testosterone have been isolated and these have been shown to retain the characteristic steroid structure (1). It is thus evident that measurement of total radioactivity following the administration of ring labelled steroid hormones is a very certain means for tracing the location or fate of the steroid nucleus. Unlike smaller molecules such as acetate or amino acids, the radioactive label in the steroid is not redistributed in the body and does not appear in compounds other than the direct metabo- lites of the hormone into which the isotope has been incorporated. This tracer technique, therefore, is much more specific for the study of the general aspects of hormone metabolism than any color reaction, no matter how great "specificity" is claimed, since in all instances these tests depend on the presence of chemical groupings which are lost or altered during in vivo biochemical transformation.

\section{Comparison of oral and intravenous administration of hydrocortisone, cortisone acetate and tes- tosterone}

The rapidity of absorption, metabolism and excretion of the end products of hydrocortisone transformation when the hormone was given orally is established by the results of experiments 2,3 , and 4 . The patient used for experiments 2 and 3 exhibited essentially the same excretory pattern in experiment 1 when the hormone was given intravenously and the latter result was in excellent agreement with the report previously published from these laboratories. From Figures 1 and 2, as well as Table II, it is clear that approximately as much radioactivity derived from hydrocortisone appeared as metabolites in the urine during the first 24 hours after oral administration as after intravenous administration in the same subject. From Figure 2, the rate at which the radioactivity derived from oral hydrocortisone is excreted was as high or higher than that for intravenously administered hydrocortisone. These results are consistent with clinical observations that oral hydrocortisone acts very rapidly. They also indicate that the absorptive processes do not delay the chemical transformations and subsequent excretion of metabolites of this adrenal hormone.

Cortisone acetate, like hydrocortisone, is effective orally and is widely used for therapy by this mode of administration. In Table II and Figure 2 it can be seen that an initially different rate of excretion was observed when the acetate of cortisone was compared with the free hormone, hydrocortisone. The data on the rate of excretion of radioactivity derived from cortisone acetate suggest that the slower rate is a consequence of the time required for the hydrolysis of the acetate ester with the release of free cortisone in the body. As hydrolysis progresses, free cortisone becomes avail- 
able for biochemical conversion and the subsequent rate of excretion of radioactive metabolites from this material seems to be quite similar to that found with hydrocortisone.

It was hoped that an examination of the mode of metabolism and excretion would indicate some reason for the relative lack of activity of oral testosterone as compared with the adrenal hormones. The data indicate that 50 to 60 per cent of testosterone-4-C ${ }^{14}$ given intravenously to male subjects is excreted in urine as metabolites within 24 hours. Since testosterone has pharmacodynamic activity in females as well as males, it was of interest to obtain data on the fate of the male hormone in women. From the data it appears that testosterone is absorbed, transformed and excreted in a similar fashion by both males and females when given either orally or intravenously. In these and other experiments, the somewhat lower recovery of radioactivity within 24 hours after testosterone as compared with hydrocortisone seems to be a constant feature of the metabolism of the androgen.

Since two routes, the portal circulation and the lymphatics, can function in absorption from the intestine, the possibility existed that testosterone and hydrocortisone were absorbed by alternative paths. Cholesterol, a precursor of the steroid hormones with a similar structure, is largely absorbed through the lymphatics in man (9) and rodents (10). Kass, Hechter, Caspi, and Hycock (11) have given evidence that cortisone did not appear in the pleural fluid of a patient with chylothorax. In order to determine directly the route of absorption, a catheter was placed in the left thoracic duct of patients and the intestinal lymph was collected. When testosterone-4- $\mathrm{C}^{14}$ and hydrocortisone-4-C ${ }^{14}$ were separately given by mouth, radioactivity appeared in the urine and was almost completely absent from lymph. The only conclusion permitted from these data is that the absorption of both testosterone and hydrocortisone occurs via the portal system rather than by way of the intestinal lymphatics. In addition to establishing the route of absorption from the gastrointestinal tract of these hormones in man, the experiments also indicate that the difference in the biological effect of testosterone and hydrocortisone after oral administration must result from other causes than the route of absorption. Since most substances undergo some chemical change such as phosphorylation, esterification or the like during the absorptive process, it is quite possible that an initial alteration by the mucosa may result in loss of activity for one hormone while the biological activity of another may be unchanged or perhaps even enhanced. This is a subject for future investigation. However, if some chemical changes during the absorptive process are not found to account for the differences in activity of oral testosterone and hydrocortisone, reactions within the liver which inactivate testosterone, but not hydrocortisone must be advanced as an explanation.

\section{Enterohepatic circulation of steroid hormones}

Having demonstrated that orally administered testosterone and hydrocortisone directly enter the human liver via the portal circulation and in view of animal evidence which indicates that intravenously administered cortisone largely localized in the liver within a few minutes (3), a study of the possible enterohepatic circulation of these hormones or their metabolic products was undertaken in three subjects with complete bile fistulas. A considerable fraction of steroid hormone radioactivity is excreted in the bile by rodents and subsequently, in the rat appears in the feces $(2,3$, 12), while the guinea pig (13) excretes this material in the urine. Man excretes the major portion of hormone metabolites in the urine. However, in the rat, when the bile duct is ligated the major portion of the derivatives of the hormone is excreted in the urine. The passage of the hormone and its metabolites through the bile and hence into the intestine is clearly an obligatory stage for the fecal excretion of hormone metabolites by the rat. It was anticipated therefore, that in man the hormone and its products either would not appear in the bile, or might be found in a form that could be readily reabsorbed from the intestine and subsequently excreted in the urine.

When hydrocortisone-4-C ${ }^{14}$ was administered intravenously at dose levels of $0.25 \mathrm{mg}$. and 100 $\mathrm{mg}$. in two separate experiments in a patient with a complete bile fistula, direct measurement of the bile failed to disclose any significant amount of radioactivity. The total amount of radioactivity 
that appeared in the urine within 24 hours was approximately the same as in an intact patient. Small quantities of hormone radioactivity, quite comparable with those of intact patients, appeared in the feces. Since similar results were obtained with the large and small doses, it is apparent that even a gross overload of hormone failed to alter the pattern by which the liver disposed of the steroid. This is clear evidence that the human species differs markedly from the rodent insofar as biliary excretion of hydrocortisone metabolites is concerned.

Radioactive testosterone was administered to a female patient with a complete bile fistula and 3 per cent of the radioactivity appeared in the bile. This was confirmed in a male subject, in whom approximately 10 per cent appeared in the bile within the first day while 51 per cent was recovered in the urine. It seems apparent from the studies on these two patients that a somewhat larger fraction of the metabolites of testosterone than of hydrocortisone appears in bile although the total excretion in this fluid is small when compared with the urinary output.

The absence of an enterohepatic circulation of hydrocortisone or its metabolites in man and the minor biliary excretion of testosterone metabolites have considerable significance for the interpretation of many studies dealing with the transformation products of these hormones and related derivatives. Thus, the possibility of metabolism of the hormones by the microorganisms of the gut can be disregarded and it can be considered established that the hormone metabolites in human urine are truly products formed by the various tissues that metabolize these compounds. The reverse of this situation is characteristic for the rodent. In the mouse, rat and guinea pig the existence of an actively operative enterohepatic circulation has been clearly defined $(2,3,12,13)$. This is particularly pertinent to studies of hormone metabolites by the guinea pig which superficially resembles man in that a major portion of the metabolites are found in the urine. Wyngaarden, Peterson, and Wolff (13) have shown, however, that most of these products were initially excreted into the gastrointestinal tract and reabsorbed before their final elimination in the urine. The role of the intestinal microorganisms in the transformations found in this species must, therefore, be kept clearly in mind, especially when comparison with the human is attempted.

The species difference in biliary elimination is very probably a consequence of a different type of conjugate formed by man and the rodents thus far studied. Evidence for this view can be found in the experiments with both testosterone and hydrocortisone. It was reported from this laboratory (2) that the urinary metabolites of testosterone in mice were for the most part persistently watersoluble products and that only a small fraction of these could be obtained in an ether soluble form even after drastic hydrolysis. A similar result has more recently been described for the biliary as well as the urinary metabolites of hydrocortisone (13) and cortisone acetate (12) in rats. Here, too, relatively little of the conjugated urinary steroids was cleaved by $\beta$-glucuronidase and even after acid hydrolysis about half the total radioactivity remained in the aqueous phase. The concordant results strongly suggest that dissimilar metabolites of these two hormones as well as conjugates other than glucuronic acid derivatives were formed. While the few metabolites that have been isolated from rodent urine are not very different from the human products these represented but a small portion of the compounds administered. There is thus reason to suggest that the difficulty in hydrolysis is associated in part with the nature of the non-steroidal portion of the complex as well as with the metabolites formed.

\section{Comparison of the fate of corticosterone and hydrocortisone}

The principal secretion of the adrenal cortex in the rodent is corticosterone whereas the principal secretion of the adrenal cortex in the human is hydrocortisone (4). The possibility, therefore, existed that if hydrocortisone were administered to a rodent or conversely if corticosterone were given to the human, these compounds might be treated as substances "foreign" to the species in which they were not the predominant adrenal secretion. This "foreign" nature of the hormone, rather than an intrinsic difference in its metabolism might account for the divergent results in the two species. Similar considerations might apply to cortisone which may also be a hormone "foreign" to the human species. Accordingly, corticosterone 
was given to the same patient with the biliary fistula who had received the testosterone and hydrocortisone, as well as to another subject (B-1) with a complete biliary fistula. Corticosterone was metabolized, conjugated and excreted in amount and time very similar to that found for hydrocortisone. Sandberg, Migeon, and Samuels (14) have briefly reported a significant excretion in human bile of radioactivity derived from corticosterone; it is not possible at present to reconcile their findings with the results obtained in this study except, perhaps, that the clinical status of the patients, particularly liver function, may have been the differentiating factor.

In patient B-1, experiment 15 , after corticosterone injection it is of particular interest to note that a relatively large amount of radioactivity, approximately 16 per cent, appeared in the feces within one day. Since there was no question about either the completeness of the biliary drainage or the absence of radioactivity in the bile, this radioactivity either entered the feces through the intestine or may have been the result of a chance radioactive contamination either on the ward or in the laboratory or is a finding related to the particular patient's clinical condition. The finding is different from the results in all other patients and an explanation cannot be offered for the fact at this time.

From the results obtained with all these steroid hormones there is no evidence for an effective enterohepatic circulation of these compounds or their metabolites in man.

\section{Concluding remarks}

The rates of excretion of conjugated radioactive metabolites for several hormones (Figures 2, 3, and 5) are quite similar, despite the fact that the total material recovered is somewhat different for each. A mechanism which may account for this similarity is one in which the kidney clears the conjugated hormone metabolites from a body compartment of constant but unknown size. This implies that the sum of the metabolic processes preceding the entrance of the transformed hormones into this particular physiologic space are both equivalent and rapid in all subjects. It may be presumed that the altered and conjugated hormone is in a space which, at a minimum, is the size of the extracellular fluid and may approach that of the total body water. The urinary steroids, which are almost exclusively in the form of conjugates, must be derived from this body compartment. The rate of excretion of the conjugated metabolites of these hormones would depend on the constant factors of the volume of the body compartment and clearance by the kidneys; the much more rapid rates which describe the immediate transformation of the hormone would not be apparent in the rate curve of excretion.

The data indicate that the liver occupies a central role in the metabolism of the steroid hormones and that the initiation of the unique biochemical processes which characterize the physiological activities of the hormones and the metabolic transformation of the steroid itself, occur within a very brief period of time. These very rapid processes in which the hormone triggers biochemical reactions in the body and either simultaneously or within a short time undergoes chemical transformation, are obscured in the gross excretion of the hormone and its metabolites. These studies, then, serve to emphasize the importance of identification of the various chemical transformation products of hormones as well as the necessity for more intensive study of the reactions of the hormones within a few minutes after administration. Perhaps by these means differences in hormone action as well as the etiological relationships of chemical disorders in hormone metabolism to disease can be brought into a coherent scheme along with the other information available on the problem of hormones. Some data concerned with the chemical nature and the amount of certain classes of hormone metabolites which constitute the "steroid pattern" have already been reported (15, 16) ; extension of these and related studies should yield important information.

\section{SUMMARY}

1. The absorption, distribution, biochemical alteration and excretion of steroid hormone metabolites have been studied in man following the oral or parenteral administration of labelled hydrocortisone, cortisone acetate, corticosterone, and testosterone.

2. In studies on subjects in whom the thoracic duct was cannulated, it was established that the 
portal system is the route through which orally administered hydrocortisone and testosterone are absorbed.

3. There was no appreciable excretion of metabolites of these steroid hormones in the bile of patients with complete biliary fistulas. The absence of an enterohepatic circulation in the human represents a significant species difference when compared with the rodent where biliary excretion is obligatory.

4. Labelled steroid metabolites appear in the urine in the same quantities and at similar rates following oral or intravenous administration of hydrocortisone.

5. The lack of biological effect following the oral administration of testosterone compared with the parenteral route was shown to be unrelated to the rate or extent of absorption since the excretory pattern was the same in male and female subjects following either oral or intravenous labelled testosterone.

6. In spite of the extremely rapid excretion of the major portion of the steroid hormones studied, it was shown unequivocally that virtually all of the excretory products represented chemically altered metabolites of the original hormone.

7. These studies indicate that the reactions in which the hormone participates in order to exert its unique physiological activity occur within a short time following either the secretion or introduction of the steroid into the body.

\section{ACKNOWLEDGMENTS}

The authors are pleased to acknowledge the technical assistance of Ursel Blumenheim, Chrysie Costantakos, Hilda Denman, Ruth Loevinger and Julie Chen.

\section{REFERENCES}

1. Gallagher, T. F., Bradlow, H. L., Fukushima, D. K., Beer, C. T., Kritchevsky, T. H., Stokem, M., Eidinoff, M. L., Hellman, L., and Dobriner, K., Studies of the metabolites of isotopic steroid hormones in man. Recent Progress in Hormone Research, 1954, 9, 411.

2. Barry, M. C., Eidinoff, M. L., Dobriner, K., and Gallagher, T. F., The fate of $\mathrm{C}^{14}$-testosterone and $\mathrm{C}^{14}$ progesterone in mice and rats. Endocrinology, 1952, 50, 587.
3. Bradlow, H. L., Dobriner, K., and Gallagher, T. F., The fate of cortisone-t in mice. Endocrinology, 1954, 54, 343.

4. Bush, I. E., The paper chromatography of steroids and its application to assay problems. Ciba Foundation Colloquia on Endocrinol., 1953, 5, 203.

5. Bierman, H. R., Byron, R. L., Jr., Kelly, K. H., Gilfillan, R. S., White, L. P., Freeman, N. E., and Petrakis, N. L., The characteristics of thoracic duct lymph in man. J. Clin. Invest., 1953, 32, 637.

6. Hellman, L., Bradlow, H. L., Adesman, J., Fukushima, D. K., Kulp, J. L., and Gallagher, T. F., The fate of hydrocortisone-4-C $\mathrm{C}^{14}$ in man. J. Clin. Invest., 1954, 33, 1106.

7. de Courcy, C., Bush, I. E., Gray, C. H., and Lunnon, J. B., A chromatographic investigation of $\Delta^{4}-3-$ ketosteroids and $\alpha$-ketolic steroids in human urine. J. Endocrinol., 1953, 9, 401.

8. Fukushima, D. K., Leeds, N. S., Bradlow, H. L., Kritchevsky, T. H., Stokem, M. B., and Gallagher, T. F., The characterization of four new metabolites of adrenocortical hormones. J. Biol. Chem., 1955, 212, 449.

9. Hellman, L., Rosenfeld, R. S., and Gallagher, T. F., Unpublished data from this laboratory.

10. Chaikoff, I. L., Bloom, B., Siperstein, M. D., Kiyasu, J. Y., Reinhardt, W. O., Dauben, W. G., and Eastham, J. F., C $\mathrm{C}^{14}$-cholesterol. I. Lymphatic transport of absorbed cholesterol-4-C $\mathrm{C}^{\mathbf{1 4}}$. J. Biol. Chem., 1952, 194, 407.

11. Kass, E. H., Hechter, O., Caspi, E. Y., and Hycock, $R$. R., The route of absorption of orally administered cortisone in a patient with chylothorax. J. Clin. Endocrinol. \& Metab., 1955, 15, 167.

12. Bocklage, B. C., Doisy, E. A., Jr., Elliot, W. H., and Doisy, E. A., Absorption and metabolism of cortisone-4-C ${ }^{14}$ acetate. J. Biol. Chem., 1955, $212,935$.

13. Wyngaarden, J. B., Peterson, R. E., and Wolff, A. R., Physiologic disposition of radio metabolites of hydrocortisone-4-C $\mathrm{C}^{14}$ in the rat and guinea pig. J. Biol. Chem., 1955, 212, 963.

14. Sandberg, A. A., Migeon, C., and Samuels, L. T., Distribution of radioactive hydrocortisone (compound F) and radioactive corticosterone (compound B) in human subjects. J. Clin. Endocrinol. \& Metab., $1955,15,851$.

15. Kappas, A., Dobriner, K., and Gallagher, T. F., Studies in steroid metabolism. XXVII. A comparison of the steroid response to ACTH and cortisone in normal young men. J. Clin. Invest., 1955, 34, 1559.

16. Kappas, A., and Gallagher, T. F., Studies in steroid metabolism. XXVIII. The $\alpha$-ketosteroid excretion pattern in normal females and the response to ACTH. J. Clin. Invest., 1955, 34, 1566. 